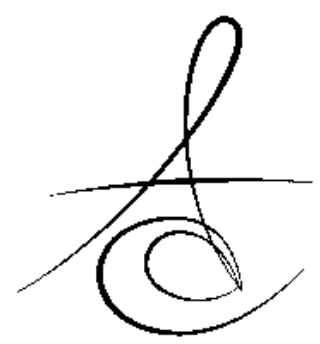

\section{DİŞ HEKİMLİĞİNDE KULLANILAN ÖLÇÜ SİSTEMLERİNDE GÜNCEL YAKLAŞIMLAR: DİJİTAL ÖLÇÜ}

\section{CONTEMPORARY APPROACHES TO DENTAL IMPRESSION SYSTEMS: DIGITAL IMPRESSION}

\author{
Yrd. Doç. Dr. İpek ÇAĞLAR*
}

Prof. Dr. Zeynep YEŞíL DUYMUŞ*

\section{ÖZET}

Sabit protetik diş tedavilerinde prepare edilen bölgenin negatifini en doğru şekilde elde etmek yapılacak olan restorasyonun başarısını doğrudan etkilemektedir. Bu nedenle preparasyon hassasiyeti kadar, kullanılan ölçü maddesi ve ölçü tekniğine de önem vermek gerekmektedir. Ölçü maddeleri yıllar içerisinde en doğru, en hassas detayı kaydedebilmek için değişimlere uğramışlardır. Yapılan çalışmalar ile boyutsal stabiliteleri, yırtılma dirençleri, biyouyumlulukları gibi birçok fiziksel ve kimyasal özellikleri iyileştirilmeye çalışılmıştır. Buna rağmen elde edilecek ölçü için klinisyenin becerisi, ortam şartları, ölçünün saklanma koşulları gibi sayısız dış etkenin de mevcut olduğu unutulmamalıdır.

Bilgisayar destekli dizayn ve tasarım (Computer Aided Manufacturer And Design; CAD/CAM) teknolojisindeki gelişmeler, bu sistemlerin diş hekimliğinde kullanımını son yıllarda önemli ölçüde artırmıştır. CAD/CAM sistemlerinde geliştirilen yenilikler arasında dijital okuma da yer almaktadır. Dijital okuma; konvansiyonel ölçü tekniklerinin istenmeyen özelliklerini ortadan kaldıran, hem hekim, hem de hasta için oldukça pratik bir ölçü alma işlemine olanak sağlamaktadır. Diş hekimliğinde piyasada bir çok firma CAD/CAM sistemlerine ilave olarak ağız içi veya ağzı dışı tarayıcılar ekleyerek laboratuvar ve klinik ortamda oluşabilecek sorunları minimalize etmeyi hedeflemektedir.

$\mathrm{Bu}$ derleme, dünden bugüne kullanılan ölçü maddelerinden bahsederek, son yıllarda popüler olan dijital ölçü teknikleri ile karşılaştırılmalı olarak değerlendirilmek ve ölçü alma işlemindeki yenilikleri geniş bir yelpazede incelemek amacı ile hazırlanmıştır.

Anahtar Kelimeler: CAD/CAM, dijital ölçü,

Yrd. Doç. Dr. Sabit Melih ATEŞ* ölçü teknikleri

\section{ABSTRACT}

The accuracy of obtaining negatives of preparation region directly affects the success of the restoration in fixed prosthetic tooth treatment. Therefore, impression materails and techniques should be taken into consideration as much as sensibility of preparation. Over the years, impressions materials have undergone change in order to provide most accurate and precise detail. Physical and chemical properties like dimensional stability, tear strength and biocompatibility have been tried to increase by conducting new studies. However, presence of numerous external factors such as ability of the clinician, environmental conditions, storage conditions of impression metarials should not be forgetten while taking an impression.

The use of Computer Aided Manufacturer And Design (CAD/CAM) technologies in dentistry are increased by the development of this systems. Digital scanner is one of the reforms of CAD/CAM systems. Digital scanner which extinguish unwanted properties of conventional impression tecniques provides possibility of taking easy impression for dentist and patients. In dental market multiple companies aim to minimalize the problem that might happen in clinic or laboratory by adding intraoral or extraoral digital scanner to CAD/CAM systems.

The aim of this rewiev is to evaluate the populer impression tecniques, to compare them with old techniques and examine the novelty of impression in wide aspects.

Key Words: CAD/CAM, digital impression, impression techniques

*Recep Tayyip Erdoğan Üniversitesi Diş Hekimliği Fakültesi, Protetik Diş Tedavisi Anabilim Dalı 


\section{GİRİş}

Prepare edilmiş veya edilmemiş dişlerden, dental implantlardan, dişsiz ağızlardan veya ağız içi defektlerden doğru ve eksiksiz ölçü elde etme işlemi, sabit veya hareketli protezlerin yapım aşamalarındaki önemli basamaklardan birini oluşturmaktadır. Ölçü işlemi; çeşitli maddeler ve uygulamalarla preparasyon sahasının veya ağız içinin ya da herhangi bir bölgenin tam negatifinin elde edilmesi anlamına gelmektedir., ${ }^{1,2}$ Restorasyonların başarısı uygulanan ölçü tekniğine ve kullanılan ölçü maddelerine de bağlıdır. ${ }^{3}$ Sabit protezlerde ölçü işleminin doğruluğu restorasyon ile dayanak diş arasındaki uyum ile değerlendirilir. Ölçü ne kadar doğru alınırsa restorasyonun uyumu o oranda artacaktır. Marjinal ve internal uyum, hazırlanacak restorasyonun kalitesini ve doğruluğunu belirleyen en önemli özelliklerindendir. Marjinal uyumsuzluklar; periodontal problemlere, çürük oluşumuna, plak tutulumuna, yapıştırıcı simanın çözünmesine veya renk değişikliği gibi başarısızlıklara neden olabilmektedir. Ayrıca aksiyel ve oklüzal alanlarda oluşan uyumsuzluklar (internal uyumsuzluk) restorasyonların kırılmaya karşı direncinin azalmasına neden olmaktadır. ${ }^{4-8}$ Gözle görülemeyen veya dental aletlerle algılanamayan marjinal uyumsuzlukların klinik olarak kabul edilebilir olduğu düşünülmektedir. Yapılan çalışmalarda 100 ile $150 \mu \mathrm{m}$ arasındaki marjinal açıklıklar, klinik olarak kabul edilebilir olarak değerlendirilmiştir. ${ }^{9-13}$

İnternal aralığın $70 \mu m^{\prime}$ den fazla olmasının dental restorasyonların kırılma direncini azalttığını vurgulayan çalışmalar bulunmaktadır.9,13 Marjinal ve internal uyumu değerlendirmek için yapılan çalışmalar incelendiğinde; genellikle konvansiyonel ölçü teknikleri ile elde edilen restorasyonların kullanıldığı, son yıllarda popüler olan dijital ölçü sistemleri ile hazırlanan restorasyonları kullanan kısıtlı sayıda çalışmanın bulunduğu belirlenmiştir. ${ }^{14}$

Uygun olmayan materyal veya koşullarda alınan ölçüler, biyolojik ve mekanik komplikasyonlar oluşturabilecek uyumsuz protetik restorasyonların hazırlanmasına sebep olmaktadır. ${ }^{15}$

Bu derlemede; ölçü tekniklerinin ve malzemelerinin gelişimi konusunda bilgi verilecek, dijital görüntüleme sistemleri tanıtılacak, karşılaştırılmalı olarak başarı ve uyumları tartışılacaktır.

\section{Ölçü malzemelerinin tarihsel gelissimi:}

Hidrokolloid ölçü maddeleri 1950 ve 1960 ’ı yıllarda sabit protetik restorasyonlarda ölçü almak için kullanılmışlardır. Daha sonraki yıllarda polisülfit ve kondensasyon silikonların piyasaya sunulması ile hidrokolloid ölçü maddelerinin sabit protetik restorasyonlarda kullanımı terk edilmeye başlanmıştır. Bu iki materyalin boyutsal stabilite ve yırtılmaya karşı dirençlerinin hidrokollidlerden daha iyi olduğu bilinmektedir. Hidrokolloidler hidrofilik özellik gösterirken polisülfit ve kondensasyon silikonlar hidrofobik özellik göstermektedirler. Polisülfit ölçü maddelerinin sertleşme sürelerinin uzun ve kokularının hoş olmaması, polimerizasyon sırasında büzülme gibi olumsuz özellikleri klinik uygulamalarda kullanımlarını azaltmıştır. ${ }^{1,16}$ Kondensasyon silikonlar tatsız ve kokusuz olmalarından dolayı daha çok tercih edilmektedirler.

Polieter ölçü maddeleri 1960'lı yıllardan sonra geliştirilmişlerdir. Polieter ölçü maddelerinin; polimerizayon büzülmelerinin az olması, yüksek boyutsal stabilite ve hidrofilik özellik göstermeleri kullanım avantajı sağlarken, rijiditelerinin fazla olması ve kontrolsüz akma gibi özellikleri kullanımlarında kısıtlamalara yol açmıştır. ${ }^{1,3}$

Kondensasyon silikonların modifikasyonu olarak ortaya çıkan ilave reaksiyonlu silikonlar ise (polivinil siloksan-PVS) 1970'i yıllarda kullanılmaya başlanmıştır. Hidrofobik özellikteki bu materyal mükemmel fiziksel özelliklere sahiptir. ${ }^{3}$

Christensen $^{17 \prime}$ in 1997 yılında yaptığı çalışmada sabit, hareketli ve implant üstü protezlerde kullanılan ölçü maddeleri kullanım sıklıklarına göre; polivinil siloksan, polieter ve irreversible hidrokolloidler olarak sıralanmışlardır.

Ölçü maddelerindeki değişim ve gelişmeler daha uyumlu restorasyonların elde edilebilmesi için yapılmaktadır. Klinisyenin beceri ve bilgisinin etkili olduğu konvansiyonel ölçü sistemlerinde birçok başarısızlık oluşabileceği gibi, klinisyenden bağımsız olarak ölçü maddelerinin distorsiyonu, kaşıktan ayrılması veya kopması, saklanma koşulları, ölçü alınan yüzeydeki kan ve tükürük gibi birçok olasılık, hazırlanan restorasyonlarda başarısızlığa sebep olabilmektedir. ${ }^{18-21}$

Ölçü işleminin kalitesinin en iyi düzeye getirilmesinin yapılacak restorasyonun uyumunu arttırdığı unutulmamalıdır. Yeni geliştirilen bilgisayar destekli sistemlerle hastalar ve hekimler için ölçü alma işleminin daha basit hale getirilmesi ve ölçü alma sırasında oluşabilecek hataların minimuma indirgenmesi hedeflenmektedir. 


\section{Dijïtal ölçülerin gelissimi:}

Bilgisayar destekli üretim ve tasarım (Computer Aided Manufacturer And Design; CAD/CAM) prosedürlerinin protetik diş tedavisi alanına girmesi ile birlikte dijital iş akışı terimi gündeme gelmiştir. ${ }^{14}$ Dental restorasyonların üretim ve dizaynının yapıldığı CAD/CAM teknolojisi; verilerin toplanarak kaydedilmesi, geleneksel kurallara uygun olarak seçilen restorasyonun tasarımının bilgisayar yardımı ile hazırlanması (CAD) ve restorasyonun üretilmesi (CAM) olmak üzere üç fonksiyonel bölümden oluşmaktadır. 22,23 Verilerin toplama işlemi her sisteme göre farkllıklar göstermektedir. Bazı sistemlerin kendine ait ağız içi kameraları mevcut iken, genellikle veriler mekanik ve optik sayısallaştııııılar kullanılarak model üzerinden elde edilmektedir. ${ }^{22-24}$ Dijital sistemlerle görüntüleme; teknisyenin aktif olduğu indirek teknik ve hekimin aktif olduğu direk teknik ve olmak üzere iki grupta değerlendirilebilir. ${ }^{4}$

\section{İndirek Teknik:}

$\mathrm{Bu}$ sistemde ağız içi tarayıcı kullanılmadan konvansiyonel yöntemlerle ölçü alınır. Alınan ölçü ile elde edilen model CAD/CAM sistemine ait optik veya mekanik sistemler ile tarama işlemine tabi tutulur. Bazı sistemlerde ise; alçı model kullanılmadan alınan ölçü yüzeyinin taranması ile sanal model elde edilebilir. Sanal model üzerine istenilen restorasyon uygulanabilir. ${ }^{25}$

\section{Direk Teknik:}

Bu teknikte konvansiyonel ölçü yöntemleri tamamen ortadan kalkmışıı. Buna göre; istenilen restorasyon için hazırlanan dişler ağız içi görüntüleme sistemleri yardımı ile taranır ve bilgisayar ortamına aktarlır. ${ }^{25}$

Hassasiyet bakımından indirek teknik, konvansiyonel ölçü materyallerini ve ölçü tekniklerini içerdiğinden direk tekniğe göre farkllıklar göstermektedir. Bu nedenle; ölçü maddelerinin boyutsal stabilitesi, saklama koşulları, dezenfeksiyon sırasındaki distorsiyonlar, ölçü kaşığından ayrılması ve uyumsuzluğu, dental laboratuvara transferi sırasındaki şartlar dikkate alınmalıdır. ${ }^{18,25}$ Konvansiyonel teknikle alınan ölçü sırasında hastaya verilen rahatsızlık da indirek tekniğin dezavantajları arasındadır.

Avrupa ve Amerikadaki dental marketlerde dijital ölçü sistemleri ile ilgili birçok ürün piyasaya sürülmüştür. Halen yeni sistemler oluşturulması ile ilgili çalışmalar yapılmaktadır. Günümüzde mevcut olan başlıca sistemler aşağıda belirtilmiştir;

1. CEREC (Sirona Dental Systems; Bensheim, Almanya)

2. E4D (D4D Technologies, Richardson, Tex)

3. iTero (Cadent, Inc.; Carlstadt, NJ, USA)

4. Lava C.O.S (3M ESPE, Seefeld, Almanya)

5. Trios (3Shape, Copenhagen, Almanya). ${ }^{25}$

CEREC (Sirona Dental Systems; Bensheim, Almanya)

CEREC kelime anlamı olarak "Chairside Economical Restorations of Esthetic Ceramics" kelimelerinin baş harflerinden oluşmuştur. Hasta başında tek seansta inley restorasyon üretimine Mörmann ve Brandestini tarafından 1980 yllında başlanmıştır. Mörmann ve Brandestini'nin (Brains, Zurih) 1985 yllında 2 boyutlu tarama yapabilen görüntüleme sistemini kullanarak ilk defa hasta başında inley restorasyon yapması diş hekimliğinde bir dönüm noktası olarak kabul edilmiştir. CEREC 1 olarak piyasaya sunulan bu sistemin 1985 yllında biraz daha geliştirilmesi ile inley, onlay ve laminate veneer restorasyonlar hazırlanabilmiştir. Siemens firmasının 1994 yllında CEREC 2 sistemini geliştirmesine ve full kuron yapımına olanak sağlamasına rağmen üç boyutlu tarama yapılamamış, ${ }^{26-31} 2000$ yilında ise Sirona firması tarafindan CEREC 3 sistemi piyasaya sürülmüştür. Bu sistemde ilk defa ağız içi tarayıcı eklenmiştir. 3 boyutlu tasarım 2003 yllından itibaren programa dahil edilmiştir. Bu yeni programda, restore edilecek bölge, antogonist dişler ve fonksiyonel kayıtlar 3 boyutlu olarak görüntülenebilmektedir. ${ }^{31,32}$ Oklüzyonun sistem tarafından otomatik olarak ayarlanması ise 2005 yılında sağlanmıştır (antagonist tool özelliği). Aynı yılda laboratuarlar için büyük kolaylık sağlayacak olan harici optik model tarayıcı ünitesi'in Eos' piyasaya sürülmüştür. Bu sistem sayesinde model veya ölçü tarama işlemleri hassas bir şekilde yapılabilmiştir. ${ }^{31,33,34}$

\section{E4D Dentist:}

D4D (Dream, Design, Develop, Deliver) Technologies LLC'nin ürettiği E4D Dentist bir CAD/CAM sistemidir. Bu sistemin kendine ait dizayn merkezi (bilgisayar ve monitör), lazer tarayıcı ve freze ünitesi bulunmaktadır. Intra Oral Digitizer adı verilen tarayıcı, kısa vertikal boyu sayesinde ağız açıklı̆ı kısıtlı olan hastalarda bile rahatıkla kullanılabilmektedir. Bu sistemin en önemli avantajlarından bir diğeri herhangi 
bir yansıtıcı ajan kullanımı gerekmeksizin görüntü elde edilebilmesidir. Intra Oral Digitizer ile ağız içi görüntü elde edebildiği gibi, konvansiyonel ölçü teknikleri ile elde edilen alçı modelden veya elastomerik ölçü yüzeyinden tarama yapılarak sanal model oluşturulabilmektedir. Sanal model üzerinde planlanan restorasyon freze ünitesine aktarılır ve istenilen restorasyon hazırlanabilir. ${ }^{2}$

Cerec ve E4D Dentist sistemleri CAD/CAM sistemleri olduğundan restorasyon, sistemin kendi bilgisayar programına uygun freze cihazından elde edilebilmektedir. Bu sistemlerin dışında sadece ağız içi görüntüleme yapan sistemler de mevcuttur. Bu sistemlerle elde edilen görüntüler ile final restorasyonlar laboratuvar ortamında hazırlanır. Elde edilen görüntüler istenildiği kadar depolanabildiği için ölçünün deformasyon riski ortadan kalkmıştır. Piyasada en çok kullanılan sistemler iTero (Cadent, Inc.; Carlstadt, NJ, USA), Lava C.O.S (3M ESPE, Seefeld, Almanya) ve Trios (3Shape, Copenhagen, Almanya)'dır. 2,24,25

\section{iTero:}

iTero sistemi ile kendine ait tarayıcı kullanılarak ağız içi görüntüleme yapılabilmektedir. Bu sistemde ağız içi aparey aracılığıyla saniyenin üçte birinde üretilen 100.000 kırmızı ışık huzmesi ile dijital veri oluşturulmaktadır. Bu sistem ile ağız içi yapılara titanyum dioksit toz benzeri herhangi bir yansıtıcı ajan kullanılmaksızın görüntü elde edilebilmektedir. Sistemde sesli komut ile hekim yönlendirilmektedir. 2,35

Final görüntü elde edildikten sonra internet ortamında oluşturulan sanal modelden sert plastik model elde edilmektedir. Bu plastik model üzerinde istenilen protetik veya restoratif restorasyon yapılabilmektedir. ${ }^{36}$

\section{Lava C.O.S:}

Lava Chairside Oral Scanner sistemi 2008 yılında piyasaya sunulmuş yeni bir cihazdır. Bu ağız içi tarayıcının çalışma prensibi; üç boyutlu verilerin oluşturulmasında aktif optik dalga boyu örneklemesine (AWS) dayanmaktadır.,37 Diğer dijital ölçü tarayıcıları triangulasyon ve lazer yaklaşımlarını tercih etmektedirler. Bu sistemlerde lazer veya ışık demeti obje üzerinde yönlendirilerek üç boyutlu görüntü elde edilir. Bu teknikler yavaş olduğu kadar, distorsiyon ve optik illüzyon gibi dezavantajlara sahiptirler. AWS tekniğine dayanan Lava C.O.S sistemi, saniyede yaklaşık 20 adet üç boyutlu dijital görüntü elde etme hızına sahiptir ve yüksek doğrulukta sanal model etme imkânı sunar. ${ }^{2}$
Birçok sistem gibi bu sistemde de ağız içi yapıların görüntüsü alınmadan önce tozlanma yapılması gerekmektedir. Sistemin kendisine ait tozlanma tabancası mevcut olup gerekli alanların tozla kaplanması istenmektedir.

Trios (3Shape, Copenhagen Danimarka copenhag Almanya):

Trios ağız içi görüntü sisteminde dijital ölçü için herhangi bir yansıtıcı toz kullanımına gerek kalmadan direk olarak ağız içi dokulardan görüntü elde edilir. Elde edilen görüntülerden oluşturulan sanal modelden istenilen restorasyon, laboratuvar ortamında veya CAD/CAM sistemleri ile hazırlanır. ${ }^{38}$

Tüm bu sistemlerin avantaj ve dezavantajları bulunmaktadır. Dental ölçü algısını tamamen değiştiren dijital ölçü tekniklerinin doğruluğu ve güvenilirliği, kolaylığından daha önemli bir parametredir. Bu sistemleri kendi aralarında ya da konvansiyonel ölçü teknikleriyle karşılaştıran birçok çalışma bulunmaktadır. 38

Almeida E Silva ve ark. ${ }^{4}$ yaptıkları çalışmada konvansiyonel ölçü tekniği ile dijital ölçü tekniğinin boyutsal doğruluğunu karşılaştırmışlardır. Her iki sistemin klinik olarak kabul edilebilir değerler ortaya koymasına karşın, internal ve marjinal uyum değerlerinin Lava C.O.S ağız içi görüntüleyicide daha düşük olduğu belirlenmiştir. Dijital görüntüleme sırasında kullanılan titanyum oksit tozunun marjinal uyum değerlerini tahmin edilenden daha fazla artırdığı vurgulanmıştır. Başka bir çalışmada Lava C.O.S ağız içi görüntüleyici ile elde edilen tek kuron restorasyonların marjinal uyumlarının silikon ölçü maddeleri ile alınandan daha iyi olduğu belirtilmiştir. ${ }^{39}$

CEREC AC ve Lava C.O.S ağız içi görüntüleyiciler ile elde edilen modellere göre, kazınan zirkonya kuronların internal ve marjinal uyumlarının değerlendirildiği bir çalışmada; her iki sisteminde klinik olarak başarılı sonuçlar verdiği vurgulanmıştır. ${ }^{14}$ CEREC Bluecam ve Lava C.O.S ağız içi görüntüleyicilerin konvansiyonel ölçü sistemleri ile karşılaştırıldığı başka bir çalışmada ise Lava C.O.S sistemi ile elde edilen modellerdeki sapmaların CEREC Bluecam'den daha az olduğu ve her iki dijital görüntüleme sisteminde konvansiyonel ölçü tekniklerinden daha az sapma meydana getirdiği belirtilmiştir. ${ }^{38}$

Flügge ve ark. $^{40}$ iTero sisteminin ağız içi görüntüleyicisi ve ağız dışı görüntüleyicisi ile elde edilen modellerin doğruluğunu karşılaştırmışlardır. Ağız 
dışı görüntüleme için konvansiyonel ölçü teknikleri ile plastik modeller elde edilmiştir. Ağız dışı görüntüleyici ile elde edilen modeldeki sapma ortalamalarının, ağız içi görüntüleyici ile elde edilen modellerden daha az olduğu saptanmıştır. Özelikle her iki sistemde de alt çenedeki sapmaların üst çeneden daha az olduğu dikkat çekmiştir.

iTero, Lava C.O.S, CEREC AC ağız içi görüntüleme sistemleri, konvansiyonel tek ve çift aşamalı ölçü teknikleri ile elde edilen modeller üzerine uygulanan tek zirkonya kuron restorasyonların internal uyumu incelenmiş ve birbirleri ile karşılaştırılmıştır. Tüm bu sistemler arasında en iyi internal uyum Lava C.O.S sistemi ile elde edilen model üzerinde hazırlanan zirkonya kuronlarda elde edilmiştir. Buna rağmen bu sistemin CEREC AC sistemi dışında diğer sistemlerle arasında istatistiksel olarak anlamlı bir fark bulunamamıştır. ${ }^{41}$

Tüm bu çalışmalar ışığında güncel görüntüleme sistemlerinin doğruluğu konusunda yeni araştırmalar yapılabilir. Sistem her geçen gün geliştirilerek, negatif yönleri azaltılabilir ve doğruluğunun kanıtlanması ile birlikte dijital ölçü sistemleri daha sıklıkla tercih edilebilir.

\section{KAYNAKLAR}

1. Zaimoğlu A, Can G. Sabit protezler. $1^{\text {st }}$ ed. Ankara: 2004. p. 83-85.

2. Birnbaum NS, Aaronson HB. Dental impressions using3D digital scanners: virtual becomes reality. Compend Contin Educ Dent; 2008. p. 494, 496, 498-505.

3. Hamalian TA, Nasr E, Chidiac JJ. Impresion materials in fixed prosthodontics: Influnce of choice on clinical procedure. J Prosthodont 2011; 20:153-60.

4. Almeida E Silva JS, Erdelt K, Edelhoff D, Araújo E, Stimmelmayr M, Vieira LC, Güth JF. Marginal and internal fit of four-unit zirconia fixed dental prostheses based on digital and conventional impression techniques. Clin Oral Investig 2013; May 29. [Epub ahead of print].

5. Fransson B, Oilo G, Gjeitanger R. The fit of Procera titanium crowns. An in vitro and clinical study. Dent Mater 1985; 1:197-9.

6. Karlsson S. The fit of Procera titanium crowns. An in vitro and clinical study. Acta Odontol Scand 1993; 51:129-34.
7. Sulaiman F, Chai J, Jameson LM, Wozniak WT. A comparison of the marginal fit of In-Ceram, IPS Empress and Procera crowns. Int J Prosthodont 1997; 10:478-84.

8. Beschinidt SM, Strub JR. Evaluation of the marginal accuracy of different all-ceramic crown systems after simulation in the artificial mouth. J Oral Rehabil 1999; 26:582-93.

9. Colpani JT, Borba M, Della Bona A. Evaluation of marginal and internal fit of ceramic crown copings. Dent Mater 2013; 29:174-80.

10. Kokubo Y, Ohkubo C, Tsumita M, Miyashita A, Vult von Steyern $P$, Fukushşma S. Clinical marginal and internal gaps of Procera AllCeram crowns. J Oral Rehabil 2005; 32:526-30.

11. Frannsson B, Oilo G, Gjeitanger R. The fit of metalceramic crowns, a clinical study. Dent Mater 1985;1:197-9.

12. Nakamura $T$, Nonaka $M$, Maruyma $T$. In vitro fitting accuracy of copy-milled alumina cores and all-ceramic crowns. Int J Prosthodont 2000; 13:189-93.

13. Tuntiprawon M, Wilson PR. The effect of cement thickness on the fracture strength of all-ceramic crowns. Aust Dent J 1995; 10:17-21.

14. Brawek PK, Wolfart S, Endres L, Kirsten A, Reich S. The clinical accuracy of single crowns exclusively fabricated by digital workflow--the comparison of two systems. Clin Oral Investig 2013;17:2119-25.

15. Lee H, So JS, Hochstedler JL, Ercoli C. The accuracy of implant impressions: a systematic review. J Prosthet Dent 2008;100:285-91.

16. Shillingburg HT. Sabit protezin temelleri. 3rd ed. Quintessence Yayıncılık: 2012. p.281-8.

17. Christensen GJ. What category of impression material is best for your practice? J Am Dent Assoc 1997; 128:1026-8.

18. Christensen GJ. The challenge to conventional impressions. J Am Dent Assoc 2008; 139:347-9.

19. Touchstone A, Nieting T, Ulmer N. Digital transition: the collaboration between dentists and laboratory technicians on CAD/CAM restorations. J Am Dent Assoc 2010; 141:15S-19S.

20. Mehl A, Hickel R. Current state of development and perspectives of machine based production methods for dental restorations. Int J Comput Dent 1999; 2:9-35. 
21. Beuer F, Schweiger J, Edelhoff D. Digital dentistry: an overwiev of recent developments for CAD/CAM generated restorations. Br Dent J 2008; 201:50511.

22. Ersu B, Yüzügüllü $B$, Canay Ş. Sabit restorasyonlarda CAD/CAM uygulamaları. Hacettepe Diş Hek Derg 2008; 32:58-72.

23. Strub JB, Rekow ED, Witkowski S. Computer-aided design and fabrication of dental restoration: current systems and future possibilities. J Am Dent Assoc 2006; 137:1289-96.

24. Christensen GJ. Is now the time to purchase an inoffice CAD/CAM device? J Am Dent Assoc 2006; 137:235-8.

25. Güth JF, Keul C, Stimmelmayr M, Beuer F, Edelhoff D. Accuracy of digital models obtained by direct and indirect data capturing. Clin Oral Investig 2013; 17:1201-8.

26. Yöndem İ, Aykent F. Bilgisayar desteği ile hazırlanan dental seramikler (CAD/CAM). Hacattepe Diş Hek Derg 2008; 32:79-86.

27. Aykent F, İlbay SA. İnlay ve onlay restorasyonların Cerec Sitemi ile tek seansta uygulanması. Diş Hekimliğinde Klinik 1993; 6:85-8.

28. Mörmann $W H$, Bindl $A$. The new creavity in ceramic restorations: dental CAD/CAM Quintessence Int 1996; 27:821-8.

29. Mörmann WH, Bindl A. All ceramic, chairside computer aided design/computer aided machining restorations. Dent Clin N Am 2002; 46: 405-26.

30. Bindl A, Mörmann WH. Clinical and SEM evaluation of all ceramic chairside CAD/CAM generated partial crowns. Eur J Oral Sci 2003;111:163-9.

31. Mörmann WH. The evolution of the CEREC system. J Am Dent Assoc. 2006; 137 Suppl: 7S-13S.

32. Karataşı $B$, Tunç E. CEREC sisteminin gelişimi. J Am Dent Assoc 2006; 137: 22-31.

33. Mörmann $W H$, Brandestini $M$. The fundamental intentive principles of CEREC CAD/CAM. In Mörmann $\mathrm{WH}$, state of art of CAD/CAM restorations:20 years of CEREC. London Quintessence 2006; 1-8.

34. Fasbinder DJ. Predictable CEREC occlusal relationships. In Mörmann $\mathrm{WH}$, state of art of CAD/CAM restorations:20 years of CEREC. London Quintessence 2006; 93-100.
35. Garvey P. The dental assistant's role in integrating digital impression technology in dental practice. Dent Assit 2007; 76:12-4.

36. Cadent debuts 'next generation' iTero digital impression system. Implant Tribune, US edition 2007; 1:14.

37. Lava chairside oral scanner C.O.S 3M ESPE Technical Datasheet. http://multimedia. 3m.com/ mws/mediawebserver?mwsId $=66666 \mathrm{UgxGCuNyXT}$ tn8T_08TyEVtQEcuZgVs6EVs6E666666--\&fn= Lava_COS_IFU_\%202.0_US.pdf. Accessed 28 ocak 2014.

38. Ender A, Mehl A. Full arch scans: conventional versus digital impressions-an in vitro study. Int J Comput Dent 2011; 14:11-21.

39. Syrek A, Reich G, Ranftl D, Klein C, Cerny B, Brodesser J. Clinical evaluation of all-ceramic crowns fabricated from digital impressions based on the principle of active wavefront sampling. J Dent 2010; 38:553-9.

40. Flügge TV, Schlager S, Nelson K, Nahles S, Metzger CM. Precision of intraoral digital dental impressions with iTero and extraoral digitization with the iTero and a model scanner. Am J Orthod Dento Facial Orthop 2013; 144:471-8.

41. Seelbach P, Brueckel C, Wöstmann B. Accuracy of digital and conventional impression techniques and workflow. Clin Oral Invest 2013; 17:1759-64.

\section{Yazışma Adresi:}

Prof. Dr. Zeynep YEŞİL DUYMUŞ

Recep Tayyip Erdoğan Üniversitesi

Diş Hekimliği Fakültesi

Protetik Diş Tedavisi Ana Bilim Dalı, Rize

Tel: 04642220001

E Mail: zyesilz@hotmail.com 